\title{
Atrás del pensamiento, el mero existir: Clarice Lispector (1920-1977) y la vida como pura inmanencia
}

Behind Thought, Mere Existence: Clarice Lispector (1920-1977) and Life as Pure Immanence

\section{Susana Rosano}

IECH, Instituto de Estudios Críticos en Humanidades UNR-Conicet

Rosario, Argentina

DOI: https://doi.org/10.32719/13900102.2020.48.2

Fecha de recepción: 28 de febrero de 2020

Fecha de aceptación: 31 de marzo de 2020 


\section{RESUMEN}

Este ensayo se plantea algunas preguntas sobre una zona de la obra de Clarice Lispector que consideramos de las más complejas: la capacidad de la escritura para dar cuenta de la vida, pero de una vida que en muchas oportunidades se escapa al pensamiento racional, y permanece expuesta allí, en su mera existencia. A partir del análisis de algunos cuentos y crónicas y, fundamentalmente, de sus textos Agua viva (1973) y La hora de la estrella (1977), nos preguntamos por el planteo de Gilles Deleuze de la vida como pura inmanencia, pura potencia. Una vida que, en definitiva, se despliega indiferenciada en un mundo holístico, en comunión con los otros seres no humanos.

PaLABRAS CLAVE: Clarice Lispector, novela brasileña, bios, inmanencia, holístico.

\section{ABSTRACT}

This essay raises questions about an area of Clarice Lispector's work considered to be one of the most complex: the ability of writing to account for life, but a life that often escapes rational thought, and remains exposed there, in its mere existence. Based on the analysis of certain stories and chronicles and, particularly, of her texts Água viva (1973) and A hora da estrela (1977), we revisit Gilles Deleuze's approach to life as pure immanence, pure power. A life which unfolds, in essence, as undifferentiated from a holistic world, and in communion with other non-human beings.

KEYWORDS: Clarice Lispector, Brazilian novel, bios, immanence, holistic.

¿CÓMO ESCRIBIR SOBRE un clásico? ¿Cómo pensar una obra que fue tantas veces abordada, disecada minuciosamente, indagada por la crítica y por biógrafos y lectores de todo el mundo? Una obra difícil, que con justicia ganó para su hacedora el carácter de enigmática. Porque sin lugar a dudas Clarice Lispector es de esa clase de autores de culto cuya aura va más allá de la comprensión de su obra.

Voy a intentar en este pequeño ensayo plantear algunas preguntas sobre una zona que considero de las más complejas: la capacidad de la escritura para dar cuenta de la vida, pero de una vida que en muchas oportunidades se escapa al pensamiento racional, y permanece expuesta allí, en su mera existencia. "Atrás del pensamiento no hay palabras: se es", dice Clarice (Lispector 2010a, 42). Se trata entonces aquí de una vida que, de la mano de Gilles Deleuze, me arriesgaría a llamar como pura inmanencia, pura potencia. Una vida que, en definitiva, se extiende indiferenciada en un mundo holístico, en comunión con los otros seres no humanos:

Todo ante nosotros. Todo limpio del retorcido deseo humano. Todo como es, no como lo habíamos querido. Existiendo solamente, y todo. Del mismo modo en que existe un campo. Como las montañas. Como 
hombres y mujeres, y no nosotros, los ávidos. Como un sábado. Como solo existe. Existe. (Lispector 2011a, 36-7; "El reparto de los panes")

Soy una lectora constante, apasionada y absolutamente maravillada por la escritura de Clarice Lispector, a la que vengo leyendo y releyendo desde hace muchos años, varias décadas me animaría a decir. Y a lo largo de esta, mi propia experiencia de lectura, de constatar el deslumbramiento que su obra ha producido en pensadores de la talla de Hélène Cixous, Rosi Braidotti, Antonio Cándido, Rosario Castellanos, Silvano Santiago, me pregunto precisamente dónde está esa zona de indeterminación de la obra de Clarice que se resiste a la interpretación y que, al mismo tiempo, es lo que produce fascinación. Apuesto aquí a que se trata de una forma de aprehendimiento del mundo que nos descoloca de nuestras percepciones habituales, que desbarata nuestras maneras domesticadas, lógicas y racionales de comprender lo que nos rodea, y nos arroja a la incerteza. Como en el súbito descubrimiento del personaje del cuento "Evolución de una miopía": "Fue apenas como si se hubiese quitado los anteojos y la miopía misma le hiciese ver" (Lispector $201 \mathrm{la}$, 91; énfasis añadido).

Benjamin Moser sostiene una hipótesis arriesgada: que Clarice reescribió una y otra vez durante toda su vida la historia de su nacimiento. En los primeros capítulos de su impecable biografía sobre la autora brasileña, traducida al español hace un par de años, Moser ofrece una detallada investigación sobre los pormenores del estigma de ser judío en la Ucrania de los años veinte, de la tremenda violencia de los progroms, y de la ayuda económica que el barón Maurice de Hirsch (al que Moser presenta como "el mayor filántropo judío de su tiempo", 37) ofrecía a las familias judías para emigrar a países como Canadá, Brasil, Estados Unidos y Argentina. Constata allí a partir de varias fuentes que en Chechelnik, un recóndito rincón del enorme Imperio ruso, poco tiempo después de la Revolución de Octubre, la madre de Clarice habría sido violada y como consecuencia de ello contrajo sífilis en una época en donde todavía no se había descubierto la penicilina para tratarla. "Hay algo que me gustaría decir y que no puedo y sería difícil que alguien escriba mi biografía", Clarice sostiene en un manuscrito inédito, y solamente, muy al final de su vida, confió a su mejor amiga que su madre había sido violada antes de concebirla, por un grupo de soldados rusos (Moser 2017, 46).

Bajo la convicción de que no había característica que Clarice Lispector hubiese querido perder más que su lugar de nacimiento, la consta- 
tación de contradicciones y mentiras en las declaraciones que la escritora hizo sobre este punto a lo largo de su vida y ciertas lagunas en el relato biográfico de sus dos hermanas mayores, el biógrafo arriesga su hipótesis y concentra así en el dato biográfico, una clave de lectura.

"Pertenecer" se llama la crónica del 15 de junio de 1968 en donde Clarice habla en una de sus pocas intervenciones al respecto sobre las condiciones más desfavorables de su nacimiento: "Estoy segura de que en la cuna mi primer deseo fue el de pertenecer. Por motivos que no interesan aquí, de alguna manera yo debía estar sintiendo que no pertenecía a nada ni a nadie. Nací sin motivo" (Lispector 2011b, 89-90). Se pregunta allí precisamente si no empezó a escribir tan pronto en la vida porque al escribir "me pertenecía un poco a mí misma”, y confiesa también una alegría: la de pertenecer a su país, Brasil. Interesante afirmación si tenemos en cuenta que, aunque había llegado al Brasil en su infancia más temprana (alrededor del año, conjetura Moser), siempre fue considerada extranjera por muchos brasileros, no tanto por haber nacido en Ucrania ni por los muchos años en que vivió fuera del país acompañando en sus estadías a su marido diplomático, sino por su extraña manera de hablar: Clarice ceceaba y sus erres ásperas y guturales le conferían un acento extraño (Moser 2017, 25). A la confesión de su felicidad por pertenecer a la literatura brasileña, la escritora suma aquí la posibilidad de visualizarse a sí misma en la cuna, donde por "motivos que ni mi madre ni mi padre podían controlar, yo nací y resulté tan solo: nacida". Fue preparada para ser dada a luz de un modo "muy bonito":

Mi madre ya estaba enferma, y por una superstición muy difundida, se creía que tener un hijo curaba a una mujer de su enfermedad. Entonces fui deliberadamente creada: con amor y esperanza. Solo que no curé a mi madre. Y siento hasta el día de hoy esta carga de culpa: me hicieron para una misión determinada y fallé. Como si contasen conmigo en las trincheras de una guerra y yo hubiera desertado. Sé que mis padres me perdonaron por haber nacido en vano y haberlos traicionado en la gran esperanza. Pero yo, yo no me perdono. Querría que simplemente se hubiera cumplido un milagro: nacer y curar a mi madre. Entonces, sí: yo habría pertenecido a mi padre y a mi madre [...] La vida me hizo de vez en cuando pertenecer, como para darme la medida de lo que pierdo al no pertenecer. $Y$ entonces lo supe: pertenecer es vivir. (Lispector 2011b, 91; énfasis añadido)

Lo que no deja de asombrar en relación a esta crónica es precisamente que el nombre que le pusieron a Clarice en Chechelnik cuando nació 
haya sido precisamente Chaya, que en hebreo significa "vida" y que también tiene la connotación correspondiente de "animal" (Moser 2017, 53). Sabemos a estas alturas del desarrollo del pensamiento crítico que los biógrafos dibujan los trazos con que dan forma a sus personajes biografiados. Lo interesante es que la hipótesis de Benjamin Moser coincide con este núcleo duro que los críticos señalan en la obra de Lispector y que pensamos aquí como la inmanencia de vida. En la crónica que citamos, y frente a la culpa de no haber curado a su madre, la escritora parece buscar un atajo: escribir no es solamente la forma de pertenecer que encuentra; metonímicamente escribir es pertenecer, y pertenecer es vivir. Por tanto, podríamos plantear que escribir es vivir, pero en el sentido en que le da la escritora en Agua viva: "no quiero ser biográfica, quiero ser bio" (Lispector 2010a, 50).

\section{LA CRUDEZA DEL MUNDO}

¿Pero qué quiere decir Clarice Lispector cuando separa como dos conceptos antagónicos lo biográfico y lo bio? Me arriesgo a sugerir que esta dicotomía ya se encuentra presente en Lazos de familia, su primer libro de cuentos. En “Amor”, por ejemplo, la amenaza que siente Ana, la protagonista, cuando ve interrumpido su viaje en tranvía por el mendigo y decide bajarse en el Jardín Botánico para ser testigo del desborde de los árboles que se produce en el recinto; la "culpa" que siente este personaje cuando, súbitamente, recuerda que debe volver a su coqueto departamento de Río de Janeiro, nos aproxima a esta intuición sobre lo bio como algo mucho más abarcador que lo meramente biográfico y que al principio de este artículo me arriesgué a enunciar (tal vez a falta de un concepto más ajustado) como holístico. Ana es testigo en el Jardín Botánico del trabajo secreto de la naturaleza, un trabajo intenso que adquiere allí cierto sentido de lo ominoso. Y de este modo, su horror puede constelarse con el del pollito del cuento "La legión extranjera" que presiente su muerte "de la manera como las cosas vivas saben: a través del susto profundo" (Lispector 2011a, 109):

Inquieta, miró a su alrededor. Las ramas se balanceaban, las sombras vacilaban en el suelo. Un gorrión escarbaba la tierra. $Y$ de repente, con malestar, le pareció haber caído en una emboscada. En el Jardín se estaba haciendo un trabajo secreto, del cual ella comenzaba a darse cuenta. En los árboles, las frutas eran negras, dulces como la miel. Había en el 
piso carozos secos llenos de salientes como pequeños cerebros podridos. El banco estaba manchado de jugos rojos. Con suavidad intensa rumoreaban las aguas. En el tronco del árbol se pegaban las lujosas patas de una araña. La crudeza del mundo era tranquila. El asesinato era profundo. Y la muerte no era lo que pensábamos. (Lispector 2010b, 23 ; énfasis en el original)

Creo que en este cuento podemos leer una especie de cifra en el sentido borgeano sobre la obra de Lispector: el mundo, dice la narradora, era tan rico que se pudría. La muerte no era lo que pensábamos. En este sentido, Florencia Garramuño habla en Mundos en común de una suerte de comunidad entre lo animal y lo humano. Ya no se trataría de una metamorfosis sino de una convivencia, una indistinción o equivalencia, intercambiabilidad, entre aquello que nombra al animal y aquello que designa lo humano: "un horadamiento de la comunidad humana para ahuecar en ella un sitio en el que sea posible imaginar la convivencia entre diferentes formas de vida" (Garramuño 2015, 122). No es casual que para desplegar su hipótesis esta crítica se centre, dentro de la obra de Lispector, en el análisis de su novela Agua Viva, un texto absolutamente experimental, donde los personajes han abandonado todo recurso de individualización narrativa: se llaman "Eles" o "Elas" y desmantelan cualquier idea de anécdota o acción. Este texto, que Clarice publicó en 1973, confirma el gesto que abarca toda su obra en cuanto apunta a una indeterminación de los géneros. De hecho, Agua viva es un relato a mitad camino entre el lenguaje poético y el narrativo, entre el texto filosófico y la novela; una indagación sobre la vida que transcurre más allá del yo mismo, más allá de lo biográfico que se cierra en el dibujo de la persona. ${ }^{1}$ Algunos de los fragmentos que constituyen este relato (el inventario de flores, las historias de animales, ciertos momentos biográficos) ya habían integrado crónicas en los diarios y libros publicados en la década de los sesenta y setenta. Esta

1. Su biógrafo Benjamin Moser confirma que la brevedad de Agua viva enmascara varios años de trabajo. Una primera versión, titulada precisamente "Detrás del pensamiento: Monólogo con la vida", estaba ya completa el 12 de julio de 1971. Clarice conoció en ese entonces a Alexandrino Severino, un profesor portugués de la Universidad de Vanderbilt, y le dio el manuscrito para traducir junto a las instrucciones específicas de cómo proceder: no podía cambiar ni una sola coma. Sin embargo, un año después la escritora todavía seguía corrigiendo el original, bajo la convicción de que el texto "aún no estaba logrado" y quitando del manuscrito todas las referencias autobiográficas. (Ver Moser 2017, 337-8). 
indeterminación, esta búsqueda impersonal entre lo común y lo compartido, la presión ejercida sobre los límites de los libros, de los géneros y de la propia concepción sobre lo narrativo constituyen para Garramuño una idea de literatura expandida, cuyas fronteras desbordó Clarice mucho más allá de lo que acostumbraron los escritores de su época.

Mi interés, sin embargo, en este ensayo es pensar precisamente esa expansión no tanto en relación al concepto de literatura (es innegable que Agua viva puede ser leída como lo hace Garramuño como "novela expandida", es decir, una novela donde cabe de todo, desde episodios y acontecimientos hasta intuiciones, pensamientos y una imaginación desbordada), sino como una expansión en el concepto de vida tal cual la piensa Deleuze en tanto vida inmanente. Esta escritura de Clarice no es azarosa, ni siquiera abstracta, sino que conecta en su médula, en su núcleo duro, con el terreno de los sueños, del pensamiento, con una obsesión que la escritora ya venía desplegando en sus textos anteriores. Y en Agua viva, al estallar la trama narrativa, queda al desnudo precisamente este relato sobre el fluir de la vida en su estado inmanente:

Pero existe también el misterio de lo impersonal que es el "it": tengo lo impersonal dentro de mí y no es corrupto y putrescible por lo personal que a veces me inunda: pero me seco al sol y soy un impersonal de carozo seco y germinante. Mi personal es humus en la tierra y vive de la putrefacción. Mi "it" es duro como una piedra-guijarro. (Lispector 2010a, 44; énfasis añadido)

\section{QUÉ ES LA VIDA}

Por una extraña coincidencia, los dos últimos textos que publicaron Michel Foucault y Gilles Deleuze antes de morir tienen como fin desentrañar el concepto de vida, y sobre ellos se ha sobreimpuesto un palimpsesto de lecturas filosóficas que incluyen, entre otros, a Giorgio Agamben, Slavoj Žižek y Alain Badiou.

En "La vida, la experiencia y la ciencia", Foucault se refiere a la obra de George Canguilhem. Al retomar, dentro de una filosofía del saber, la racionalidad y el concepto, el tema de la discontinuidad en la historia de las ciencias y de la importancia del punto de vista del epistemólogo, Canguilhem vuelve a ubicar a la biología dentro de una perspectiva histórico-epis- 
temológica. Pensar filosóficamente la vida, hacer de la vida el horizonte de pertinencia de la filosofía, significa para Canguilhem revertir el paradigma objetivista. En definitiva, el ser viviente sería aquel que rebasa los parámetros objetivos de la vida: "contra la idea nazi de que existe un tipo de vida perteneciente desde un principio a la muerte, Canguilhem recuerda que la muerte misma es un fenómeno de vida" (Esposito 2006, 306; énfasis añadido). No obstante, la conclusión a la que arriba Foucault no deja de sorprender: "En última instancia, la vida es aquello que es capaz de error, de allí su carácter radical” (55). Giorgio Agamben, en su lectura de este texto, hace coincidir este alejamiento de Foucault de sus obsesiones sobre el saber y el poder, sobre la relación entre verdad y sujeto, con la apertura de un tercer eje que coincide con la cantera biopolítica, una manera diferente de aproximarse a la noción de vida (Agamben 2007, 60-3).

$\mathrm{Y}$ esta forma diferente de interrogar la vida encuentra en el último e inacabado escrito de Gilles Deleuze, "La inmanencia: una vida...", un atisbo de respuesta, precaria, donde parecen confluir todas las líneas que Roberto Esposito traza bajo el signo de una biopolítica afirmativa.

El núcleo teórico, filosófico, del breve ensayo de Deleuze reside en el punto, de convergencia pero también de divergencia, entre "la vida" y, precisamente, "una vida". Al trazar una exhaustiva genealogía de la filosofía deleuziana, Agamben se detiene en la importancia que tiene la puntuación en los textos de Deleuze. De esta manera, en "La inmanencia: una vida...", el pasaje del artículo determinado al indeterminado tiene la función de señalar la ruptura del rasgo metafísico que conecta la dimensión de la vida con la de la conciencia individual. Dice Clarice en Agua viva:

El erotismo propio de lo que es vivo está esparcido en el aire, en las plantas, en nosotros, diseminado en la vehemencia de mi voz, yo escribo con mi voz. Y hay un vigor de tronco robusto, de raíces entrañadas en la tierra viva que reacciona dándoles grandes alimentos. Respiro de noche la energía. Y todo esto en lo fantástico. Fantástico: el mundo por un instante es exactamente lo que mi corazón pide. Estoy lista para morirme y constituir nuevas composiciones [...] Y mi propia fuerza me libera, esa vida plena que se me desborda. Y nada planeo en mi trabajo intuitivo de vivir: trabajo con lo indirecto, formal, y lo imprevisto. (Lispector 2010a, 56-7; énfasis añadido)

Existe aquí una modalidad del bios irreductible, imposible de inscribir en la conciencia del sujeto, y que Deleuze (echando imprevistamente 
mano de un párrafo de Nuestro amigo común, de Charles Dickens) encuentra en la delgada línea en que la vida se encuentra con la muerte. En ese destello de vida que separa al moribundo de su subjetividad individual, y que lo expone en su simple estructura biológica, en su pura facticidad. En su absoluta singularidad, esa chispa (the spark of life en el original inglés) rebasa la esfera del individuo y se yergue en un dato impersonal (como dice Esposito, la circunstancia de que, tarde o temprano, de todos modos, se muere):

Entre su vida y su muerte, hay un momento que no es sino el de una vida que juega con la muerte. La vida del individuo le cedió lugar a una vida impersonal, y sin embargo singular, de la que se desprende un puro acontecimiento liberado de los accidentes de la vida interior y exterior, es decir, de la subjetividad y de la objetividad de lo que pasa. "Homo tantum" al que todo el mundo compadece y que alcanza una especie de beatitud. Se trata de una hecceidad, que ya no es de individuación, sino una singularización: vida de pura inmanencia, neutra, más allá del bien y del mal, porque solo el sujeto que la encarnaba en el medio de las cosas la volvía buena o malvada. La vida de dicha individualidad se borra en beneficio de la vida singular inmanente de un hombre que ya no tiene más nombre, aunque no se lo confunda con ningún otro. Esencia singular, una vida... (Deleuze 2007, 38)

En este paradójico campo trascendental deleuziano, empírico, sin conciencia, lo inmanente es en sí mismo una vida; una vida es en sí misma la inmanencia absoluta, puro acontecimiento, pura potencia. Una vida solo contiene potencias virtuales, "vida inmanente portadora de los acontecimientos o singularidades que no hacen más que actualizarse en sujetos y objetos" (38). Y en este sentido, la vida es constitutivamente impropia y por ello común como solo puede serlo la pura diferencia, la diferencia no definida por otra cosa más que por su propio diferir. En esta lógica, una vida no se conjuga en ninguna de las personas gramaticales. Se trata del problemático concepto deleuziano de lo virtual, de "la realidad de lo virtual" en Deleuze según lo lee Žižek; un pliegue donde se superponen sujeto y objeto, interior y exterior, orgánico e inorgánico. Como se dice en Agua viva:

Todo gana una especie de nimbo que no es imaginario: viene del esplendor de la irradiación matemática de las cosas y del recuerdo de las personas. Se pasa a sentir que todo lo que existe respira y exhala un 
finísimo esplendor de energía. La verdad del mundo, sin embargo, es impalpable (Lispector 2010a, 112).

\section{LA VIDA QUE SE COME LA VIDA}

"Nací así: sacando del útero de mi madre la vida que siempre fue eterna" (Lispector 2010a, 49). Si, como decíamos, la obra de Lispector hace de la mera existencia la médula de sus indagaciones, su última novela puede ser leída como una verdadera meditación sobre la nada. La hora de la estrella cuenta la historia de una vida prescindible, de esas que no suelen ser narradas: Macabea, su protagonista, es una nordestina que trabaja como mecanógrafa en Río de Janeiro, insignificante y escuálida, una mujer sin atributos, una chica incompetente para la vida. Uno de los elementos más interesantes de la novela es la singularidad metaficcional que aporta la voz en primera persona del narrador, un hombre que dice llamarse Rodrigo S. M. Además de ser testigo presencial de los hechos que cuenta, el narrador nos hace partícipes como lectores de las dificultades que enfrenta en la escritura del texto y de sus propias peripecias, como por ejemplo el dolor de muelas que lo aqueja y le dificulta escribir.

Macabea nunca hace preguntas porque adivina que no hay respuestas: Así pasaba el tiempo para esta chica. Se sonaba la nariz en el dobladillo de la enagua. No tenía esa cosa delicada que se llama encanto. Solo yo la veo encantadora. Solo yo, su autor, la amo. Sufro por ella. Y solo yo puedo decirle así: "¿Qué habrá que me pidas llorando y yo no te dé cantando?". Esa muchacha no sabía que ella era lo que era, tal como un cachorro no sabe que es cachorro. Por eso no se sentía infeliz. Lo único que quería era vivir. No sabía para qué, no se lo preguntaba. (Lispector 1989, 27-8)

A pesar de todo, Macebea encuentra un novio, Olímpico de Jesús Moreira Chávez, que según el autor tiene "el apellido de los que no tienen padre", un metalúrgico ladronzuelo con aspiraciones de diputado por el Estado de Paraíba, quien finalmente la abandona porque descubre que Gloria, la compañera de trabajo de Macabea, es mejor partido. Pero como el propio narrador-autor confiesa en el relato, no se trata aquí de una historia de pensamientos, y como Macabea no tiene ni siquiera ángel de la guarda, deberá morir en su pobreza. A pesar de los buenos augurios 
de madame Carlota, la vidente, un Mercedes amarillo atropella a Macabea y es precisamente allí, en el momento de su muerte, cuando la joven puede vivir "la hora de la estrella". Sobre las últimas páginas de la novela el narrador demora parsimoniosamente el relato de la muerte, y reconoce con alegría que todavía no ha llegado la hora en que la estrella de cine Macabea deba morir: "Tan viva estaba que se movió con lentitud y acomodó el cuerpo en posición fetal. Grotesca como había sido siempre. Aquella resistencia a ceder, pero esa voluntad de un gran abrazo". (Lispector 1989, 78-9)

Es exactamente en ese momento final donde la vida de Macabea se vuelve impropia, en el sentido en que lo piensa Deleuze. Allí, en ese preciso instante en donde vida y muerte confluyen, la nada desubjetiviza a Macabea y la reintegra al cosmos: "Y entonces... entonces un repentino grito y estertor de gaviota, de repente un águila voraz que se lleva a los aires altos la oveja tierna, el gato suave que despedaza al sucio ratón cualquiera, la vida que se come a la vida" (80). La vida que se come a la vida. La última novela de Clarice Lispector - que la escritora entrega a la imprenta pocos días antes de su propia muerte- cuenta los últimos instantes de Macabea desde el convencimiento de que la muerte es un encuentro con uno mismo: "Recostada, muerta, era tan grande como un caballo muerto" (80).

Se puede pensar aquí al animal como artefacto, como umbral de indistinción, y subrayar que la crisis de la forma animal tal como fue pensada en la modernidad corresponde al desmantelamiento de ciertas lógicas de representación y del ordenamiento de cuerpos y especies. A diferencia de las especulaciones teóricas actuales sobre la autofiguración y la era de la intimidad, la vida ya no se puede resumir en el formato del individuo (Giorgi 2014). En este sentido, la obra de Clarice Lispector se pregunta por los alcances de un bios que ya no coincide plenamente con el yo, ni tampoco se corresponde ajustadamente con la topografía de lo humano. Sin lugar a dudas, esta zona de su escritura se resiste a la matriz de lo autofigurativo y se expande, se extiende, en una pregunta más abarcadora sobre la vida, sobre la especificidad de lo viviente. La vida, lo sabía muy claramente Clarice, esconde algo irreductible al relato. La vida entonces tal cual la piensa Foucault, como eso que es capaz de error, y de allí su carácter radical. Con gran ironía, el narrador-autor de La hora de la estrella reconoce al final de la novela que Macabea lo mató: 
Ella estaba al fin libre de sí y de nosotros. No se asusten, morir es un instante, pasa de prisa, lo sé porque acabo de morir con la chica. Discúlpenme esta muerte. Es que no pude evitarla, la gente acepta todo porque ya ha besado la pared. Pero he así que de pronto siento mi último gesto de rebeldía y aúllo: iijla mortandad de los palomos!!! Vivir es un lujo.

Pronto ha pasado (Lispector 1989, 80-1).

\section{Lista de referencias}

Agamben, Giorgio. 2007. "La inmanencia absoluta". En Ensayos sobre biopolítica. Excesos de vida, compilado por Gabriel Giorgi y Fermín Rodríguez, 59-92. Buenos Aires: Paidós.

Deleuze, Gilles. 2007. "La inmanencia: una vida...”. En Ensayos sobre biopolítica. Excesos de vida, compilado por Gabriel Giorgi y Fermín Rodríguez, 35-40. Buenos Aires: Paidós.

Espósito, Roberto. 2006. Bíos. Biopolítica y filosofía. Buenos Aires / Madrid: Amorrortu.

Foucault, Michel. 2007. "La vida, la experiencia y la ciencia". En Ensayos sobre biopolitica. Excesos de vida, compilado por Gabriel Giorgi y Fermín Rodríguez, 41-57. Buenos Aires: Paidós.

Garramuño, Florencia. 2015. Mundos en común. Ensayos sobre la inespecificidad en el arte. Buenos Aires: Fondo de Cultura Económica.

Giorgi, Gabriel. 2014. Formas comunes. Animalidad, cultura, biopolítica. Buenos Aires: Eterna Cadencia Editora.

Giorgi, Gabriel, y Fermín Rodríguez, comps. 2007. Ensayos sobre biopolitica. Excesos de vida. Buenos Aires: Paidós.

Lispector, Clarice. 1989. La hora de la estrella. Traducido por Ana Poljak. Madrid: Siruela.

—.2010a. Agua viva. Traducción y prólogo de Florencia Garramuño. Buenos Aires: El cuenco de plata.

- 2010b. Lazos de familia. Traducido por Mario Cámara y Edgardo Russo. Buenos Aires: El cuenco de plata.

—.201 la. La legión extranjera. Traducción y prólogo de Paloma Vidal. Buenos Aires: Corregidor.

- 2011b. Revelación de un mundo. Selección de textos, traducción, presentación, revisión y notas de Amalia Sato. Buenos Aires: Adriana Hidalgo Editora.

—. 2012. El via crucis del cuerpo. Traducción y prólogo de Gonzalo Aguilar. Buenos Aires: Corregidor.

Moser, Benjamin. 2017. Por qué este mundo. Una biografía de Clarice Lispector. Madrid: Siruela. 